\title{
The nature of fatigue: a comparison of chronic "postviral" fatigue with neuromuscular and affective disorders
}

\author{
$\boldsymbol{0}$ \\ Simon C Wessely from King's College London describes starting out in the \\ EDITOR'S \\ CHOICE \\ early years of chronic fatigue syndrome with his first 'proper' paper
}

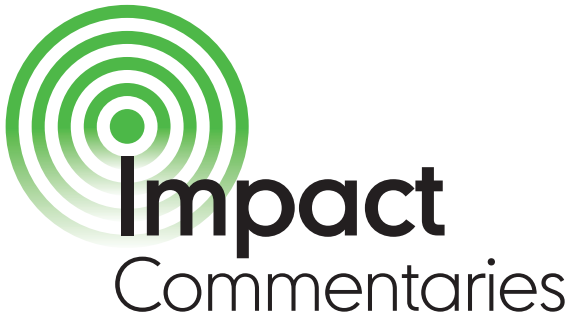

In 1987 I was a senior registrar on the Maudsley psychiatry training scheme when I was moved at short notice up to the National Hospital for Neurology, London, because the current SpR, Ray Dolan, had just been promoted to consultant. I soon expressed an interest in seeing one group of patients who were always getting referred to the liaison service, and frankly were not popular with many of the neurologists who ran the place. It wasn't the fault of the patients - they had symptoms that might have had a neurological explanation. But when the neurologists drew a blank, the patients soon got the message, whether rightly or wrongly, that the neurologists thought that they were at best suffering from depression, at worst making it all up, either of which appeared to be confirmed when the next port of call was myself. I still treasure the briefest but still most unintentionally revealing referral letter I have ever received-"Dear Simon, Please see this patient. There is nothing wrong with her".

That something was wrong was clear, but what exactly? The Americans would introduce the term chronic fatigue syndrome (CFS) a year later, which at least gave a label that doctors could use, but in 1987 it was known as 'ME', short for myalgic encephalomyelitis, which further irritated the neurologists. In the

Correspondence to Professor S Wessely, Department of Psychological Medicine, Institute of Psychiatry, King's College London, London, UK; simon.wessely@kcl.ac.uk

\author{
THE NATURE OF FATIGUE: \\ A COMPARISON OF CHRONIC \\ "POSTVIRAL" FATIGUE WITH \\ NEUROMUSCULAR AND AFFECTIVE \\ DISORDERS ${ }^{1}$ \\ Authors: S Wessely, R Powell \\ Year published: 1989 \\ Number of times cited: 344
}

media it was known as 'yuppie flu'. Some suggested it was a postviral condition, others a persistent virus similar to HIV, but the commonest from either patients or the media was that something was wrong with the muscles.

I was however struck not by the overlaps with muscle disorders but with some of the symptoms that I had seen in depressed patients before I came to Queen Square. It dawned on me that I had a wonderful opportunity to test this out, since one thing that the Square was not short of was people with well characterised neuromuscular disorders. So I decided to carry out a simple clinical study, comparing the pattern of fatigue and fatigability in the CFS patients compared with those with illnesses such as myasthenia gravis. I enlisted the help of Robin Powell, another psychiatric trainee, to recruit a second control series of patients with major depression who were being treated at the Royal Free Hospital London.

There was no instrument available to measure subjective fatigue, so I simply invented one, which would later get modified into the Chalder Fatigue Scale, which also became a citation 'hit'. And basically that was that.

What we showed was clear. The pattern of fatigue in the CFS patients was different to that seen in those with peripheral neuromuscular diseases, and instead was similar to those in the affective controls. The only time when the neuromuscular patients did look like the ME patients was when the former group also had comorbid depression. But there were also differences between the ME patients and the depressed control group that Robin had recruited, although these differences were not as great as those between the CFS patients and those with myasthenia. The CFS patients did not show core cognitive features of depression, such as guilt or self blame. We wondered if this was a reflection of their different pattern of attribution (blaming an external cause, namely a virus, rather than an internal cause, as the depressed patients did). Overall, however, our principal conclusion was that the fatigue in the 'chronic postviral fatigue' patients (as we labelled them, knowing that $\mathrm{ME}$ would be unacceptable to the journal) had a central, not peripheral, origin, and that primary muscle disease was therefore an unlikely explanation for the symptoms and disability that the patients showed.

The paper was accepted without revision-600 papers later that still hasn't happened again. I wasn't aware of citation indices back then, and it was many years before I was aware that it was indeed a citation success. I think the reasons were twofold. Firstly, it was indeed a piece of pure clinical research, and one did not need either a background in advanced neurosciences or advanced statistics to understand it. Secondly, it made sense, by which I mean that it fitted with what many clinicians already felt-that this was a genuine condition, which bore more relationship to disorders such as depression than neuropathy or myopathy. True, papers were published showing abnormalities in the muscle, but these were most likely secondary rather than primary findings.

Has the paper stood the test of time? Not badly, all told. I think we probably overestimated the links with affective 
disorder (and when I went back to the Maudsley we then did a neuroendocrine paper which was the first to suggest that there were some biological differences between major depression and $\mathrm{CFS}^{2}$ ) and underestimated the influence of anxiety. Over the years antidepressants have not proven that helpful in managing CFS, unlike the CBT model that we developed the following year. No compelling viral or immunological biomarker has been found. This is not as some claim for want of trying-as we were doing the interviews for the JNNP paper we also collected samples for a blinded study of the VP 1 antigen, which had been claimed to be a specific enteroviral marker and a test for 'ME' ${ }^{3}$ That would prove to be one of many false dawns in the story of CFS. It still seems to me that the most fruitful avenue for research is going to be via neurosciences, and understanding the nature of the sense of physical and mental effort, which is at the heart of the condition.

How have I stood the test of time? I had really enjoyed doing the research that led to the JNNP paper, and for the first time started to seriously think about a career in academic as opposed to clinical psychiatry. With help from Maria Ron, I put together a successful application for a Wellcome Training Fellowship in Epidemiology, and went to the London School of Hygiene to do the MSc and subsequent doctorate in epidemiology. I continued for the next decade to work on problems like CFS, and had some successes. We showed for example that it was not 'yuppie flu', and that it also was not untreatable. ${ }^{4}$ It wasn't plain sailing though, since it was impossible to get rid of the stigma of being a psychiatrist, which transferred itself to the patients. I found, and still find, that hard to accept, but it was a fact of life, and I became identified with the 'all in the mind' view of CFS, which was ironic since my interest in the condition was triggered by the fact that I did not think this was an imaginary or non-existent disorder, as many did at the time. Eventually I would move on academically, even though I continue to see CFS patients clinically.

I may have moved on but some things have not really changed. Re-reading the 1989 paper, I am struck by what we wrote in the discussion. In the intervening almost quarter of a century our observation on clinical bias has been partly addressed, but the rest remains as true as ever.

"It is not our intention to adjudicate between the opposing views of physical or psychological aetiology. With the expanding knowledge concerning the biological basis of many psychiatric illnesses such a division becomes increasingly meaningless. However, both patients, and some doctors, continue to insist on such distinctions. It is instead our purpose to point out the serious consequences that result from this division. Not only will this lead to bias in research based on general hospital samples (as most has been), but it also suggests that many patients are being deprived of effective treatment".

Any lessons? You can do important research with minimal resources. We never had a grant for it - the only costs were those of photocopying the questionnaires, which I used to do on the ward in the evening when the rather fierce ward clerk had gone home. I am still waiting for the bill.

Competing interests None.

Provenance and peer review Commissioned; not externally peer reviewed.

Accepted 17 August 2011

J Neurol Neurosurg Psychiatry 2012;83:4-5. doi:10.1136/jnnp-2011-301216

\section{REFERENCES}

1. Wessely S, Powell R. Fatigue syndromes: a comparison of chronic "postviral" fatigue with neuromuscular and affective disorders. J Neurol Neurosurg Psychiatry 1989;52:940-8.

2. Cleare A, Bearn J, Allain T, et al. Contrasting neuroendocrine responses in depression and chronic fatigue syndrome. J Affect Disord 1995;35:283-9.

3. Halpin D, Wessely S. The VP-1 antigen in chronic postviral fatigue syndrome: a controlled study. Lancet 1989;i:1028-9.

4. Bonner D, Butler S, Chalder T, et al. A follow up study of chronic fatigue syndrome. J Neurol Neurosurg Psychiatry 1994;57:617-21. 